\title{
Characterization of pectins extracted from pomegranate peel and their gelling properties
}

\author{
Mouna Abid ${ }^{\mathrm{a}}$, S. Cheikhrouhou ${ }^{\mathrm{a}}$, Catherine M.G.C. Renard ${ }^{\mathrm{b}}$, Sylvie Bureau ${ }^{\mathrm{b}}$, Gérard Cuvelier ${ }^{\mathrm{c}}$, \\ Hamadi Attia ${ }^{a}$, M.A. Ayadi ${ }^{\text {a,* }}$ \\ a Laboratoire Analyse, Valorisation et Sécurité des Aliments, Université de Sfax, Ecole Nationale d'Ingénieurs de Sfax (ENIS), BP 1173-3038 Sfax, Tunisia \\ ${ }^{\mathrm{b}}$ UMR408 SQPOV Sécurité et Qualité des Produits d'Origine Végétale, INRA, Avignon Université, F-84000 Avignon, France \\ ${ }^{\mathrm{c}}$ UMR Ingénierie Procédés Aliments, AgroParisTech, INRA, Université Paris-Saclay, F-91300 Massy, France
}

Keywords:

Punica granatum $\mathrm{L}$.

Extraction

Pectin

Chemical composition

Rheological properties

\begin{abstract}
A B S T R A C T
The composition of pomegranate peel, the main by-product during pomegranate processing, and some of the characteristics of the water-soluble pectins were investigated. Four tunisian pomegranate peels were subjected to hot aqueous extractions $\left(86^{\circ} \mathrm{C}, 80 \mathrm{~min}, 20 \mathrm{mM}\right.$ nitric acid). Pomegranate peels yielded between $6.8 \%$ and $10.1 \%$ pectins. The extracted pectins were low methylated and were characterized by the predominance of homogalacturonan regions. Principal component analysis applied on FT-IR spectral data in the region between 4000 and $650 \mathrm{~cm}^{-1}$ differentiated the samples according to their degree of methylation. At $\mathrm{pH} 3$, in the presence of $0.7 \%$ pectin, all solutions showed a rapid gel formation with $\mathrm{G}^{\prime}>\mathrm{G}^{\prime \prime}$. With decreasing temperature from $90^{\circ} \mathrm{C}$ to $10^{\circ} \mathrm{C}, \mathrm{G}^{\prime}$ increased to reach a plateau at $10^{\circ} \mathrm{C}$. The variation in the pectin gel formation between varieties was attributed to difference in pectin characteristics particularly the hydrodynamic volume and the neutral sugar content.
\end{abstract}

\section{Introduction}

Pectin is a gelling biopolymer originating from plants, and is an essential component in initial cell growth as well as in the ripening process. Pectin is mainly present in the primary cell wall and in the middle lamella of plants, and makes up around 40\% (dry matter basis) of the cell wall of fruits and vegetables (Brett \& Waldron, 1996). Pectin is also one of the gelling agents added to food products to achieve desired texture or consistency, particularly in jam and jelly manufacturing (May, 1990).

The pectin chain structure mainly consists of $\alpha-(1-4)-$ D-galacturonic acid units forming long homogalacturonic chains interspersed by rhamnogalacturonan sections where rhamnose and galacturonic acid residues alternate. Neutral sugar units are attached to the backbone and concentrated in highly branched "hairy" regions (Voragen, Pilnik, Thibault, Axelos, \& Renard, 1995). Part of the carboxylic groups in the galacturonic chain exists in methyl ester form, and the degree of methylation (DM) divides pectin into two types. In the high-methoxyl (HM) form, more than $50 \%$ of the carboxyl groups are methylated, while in the

\footnotetext{
* Corresponding author.

E-mail addresses: ayadimedali@yahoo.fr, ayadimedali@gmail.com (M.A. Ayadi).
}

low-methoxyl (LM) form less than $50 \%$ are methylated. The degree of methylation is crucial for the gel formation of pectin. Low methoxyl (LM) pectins are often used in low-sugar products due to their gel-forming properties without or with a small amount of sugar and in the presence of $\mathrm{Ca}^{2}{ }^{+}$. At high sucrose concentrations LM pectin tends to pregel (May, 1990). Gel formation of LM pectin occurs over a wide range of $\mathrm{pH}$ values, and the efficient $\mathrm{Ca}^{2+}$-binding is an important factor both at low and high $\mathrm{pH}$ values. The distribution of free and esterified carboxyl groups in the pectin backbone affects the strength of the $\mathrm{Ca}^{2+}$-binding and thus the functionality of both LM and HM pectin gels (Logfgren, Guillotin, Evenbratt, Schols, \& Hermansson, 2005).

The proposed mechanism for LM pectin gelation is based on the so-called egg-box model, with formation of gel networks through ionic cross links with divalent cations, usually calcium. These junction zones are also stabilized by hydrogen bonds and include highly retained water molecules (Braccini \& Perez, 2001).

The microstructure and rheology of pectin gels are affected by several parameters, such as sucrose content, $\mathrm{pH}$, temperature, and $\mathrm{Ca}^{2+}$ ion concentration.

The gelling ability of pectin depends on its solubility and viscosity, which are a measure of its molecular weight (Rao, 1993). The viscosity depends not only on the concentration of the polymer but also on the molecular weight and shape, $\mathrm{pH}$ and ionic strength. 
The higher the molecular weight, the higher is its viscosity and hence, the better is its grade (Rao, 1993).

The major sources of commercial pectins are citrus wastes (pulp and peel), and apple pomace, while some specific products may be extracted from sugar-beet pulp (Arslan \& Kar, 1998).

In Tunisia, the total annual production of pomegranate (Punica granatum L.) was 71.597 tons in 2010 (Ayed, 2011). In recent years, pomegranate is increasingly consumed as various products such as juices, jams and jellies. In pomegranate juice industry, 1 ton of fresh fruit generates $669 \mathrm{~kg}$ by-product containing $78 \%$ peel and $22 \%$ seeds (Qu et al., 2009). Pomegranate peels, remaining as a valuable by-product, was studied for its antibacterial, antioxidant and anti-allergic activities (Panichayupakaranant, Tewtrakul, \& Yuenyongsawad, 2010). However, little attention was devoted to the study of pectin fraction from pomegranate peel.

The objective of this research was to examine the physicochemical characteristics and the gelling properties of pectins extracted from different Tunisian ecotypes of pomegranate peel.

\section{Materials and methods}

\subsection{Plant material}

Pomegranate fruits, ecotypes “Acide” (Ac), "Gabsi” (Ga), "Nebli” (Ne) and "Tounsi" (To), were collected from the same oasis at Gabes region (southeast of Tunisia) at mature stage. Fruits were manually peeled then the collected peels were ground into small pieces (particles' size were $1-3 \mathrm{~mm}$ ) and stored at $-12{ }^{\circ} \mathrm{C}$ for further physicochemical characterization.

Samples were dried at $50{ }^{\circ} \mathrm{C}$ until constant weight, ground and milled through 0.5 and $1.25 \mathrm{~mm}$ sieves. Final powders with sizes between 0.5 and $1.25 \mathrm{~mm}$ were retained for pectin extraction.

\subsection{Pectin extraction}

Pomegranate peel pectin was extracted with nitric acid solution $\left(\mathrm{HNO}_{3}\right.$ ) (solid-liquid ratio; $1: 50 ; \mathrm{g} / \mathrm{mL}$ ). The mixture was stirred at 400 rpm (Stirrer Heidolph RZR 20051 electronic, Germany) using optimal extraction conditions obtained in a previous work ( $80 \mathrm{~min}, 86^{\circ} \mathrm{C}$ and $20 \mathrm{mmol} / \mathrm{L}$ nitric acid). The resulting slurries were allowed to cool to room temperature $\left(25^{\circ} \mathrm{C}\right)$ and filtered through cheesecloth. Two volumes of $96 \% \mathrm{w} / \mathrm{w}$ ethanol were added to the filtrate for pectin precipitation and the obtained mixture was kept for $1 \mathrm{~h}$ at $4{ }^{\circ} \mathrm{C}$. After centrifugation at $8000 \times g$ for $20 \mathrm{~min}$ at $10^{\circ} \mathrm{C}$, the pectin precipitate was washed with $50 \%, 75 \%$ and two times with $100 \%$ ethanol and centrifuged at $5000 \mathrm{~g}$ for $10 \mathrm{~min}$ at $10^{\circ} \mathrm{C}$. Finally, the obtained pectin was dried at $45^{\circ} \mathrm{C}$ to a constant weight, ground in a mortar and subjected to further analyses. The gravimetric yield extraction was estimated as the ratio between the weight of the powdered pectin and the weight of the flour raw material $(\%, w / w)$, both on a dry basis.

\subsection{Physico-chemical characterizations}

Proximate composition of the raw material (moisture content, lipid, ash and protein content) was determined according to the method described by the Association of Official Analytical Chemists (AOAC, 1997). Dry matter was determined by drying samples at $105 \pm 3{ }^{\circ} \mathrm{C}$ to constant weights (AOAC, 1997). The total ash was determined by calcination in muffle furnace at $550^{\circ} \mathrm{C}$ until constant weight was obtained (AOAC, 1997). The total nitrogen concentration was obtained using Kjeldahl method (AOAC, 1997), and the protein concentration was estimated using a nitrogen conversion factor of 6.25. Total, soluble and insoluble fibre contents were determined according to the AOAC enzymatic-gravimetric method of Prosky, Asp, Schweizer, De Vries, and Fruda (1988). Fat content was determined by Soxhlet extraction with hexane at boiling point of the solvent (AOAC, 1997). Soluble sugars content was determined by the phenol-sulfuric acid method of Dubois, Gilles, Hamilton, Rebers, and Smith (1956) after extraction with ethanol solution $96 \%$ (v:v). The insoluble sugars content was determined by the same method after hydrolyse of the insoluble fraction with chloridric acid $(30 \%)$ at $60{ }^{\circ} \mathrm{C}$ for $2 \mathrm{~h}$. The total sugars content is the sum of soluble and insoluble sugar. Individual neutral sugars (NS) were measured as alditol acetates with inositol as an internal standard (i) in the pomegranate peel after prehydrolysis in $250 \mu \mathrm{L}$ of $72 \%$ sulfuric acid ( $1 \mathrm{~h}$, room temperature) followed by hydrolysis with $1 \mathrm{~mol} / \mathrm{L}$ sulfuric acid $\left(3 \mathrm{~h}, 100^{\circ} \mathrm{C}\right)$ and (ii) in the pectins extracts after hydrolysis in $1 \mathrm{~mol} / \mathrm{L}$ sulfuric acid $\left(3 \mathrm{~h}, 100^{\circ} \mathrm{C}\right)$. After hydrolysis, they were derivatized to alditol acetates (Englyst \& Cummings, 1984). They were injected on a gas chromatography-flame ionization detector HP5890 Series II (Agilent, Inc., Palo Alto, CA) with a capillary column of $30 \mathrm{~m} \times 0.25 \mathrm{~mm}$ i.d. coated with DB225 mass spectrometry (MS), having a $0.25 \mathrm{~mm}$ film thickness (J\&W Scientific, Agilent, Inc.). The conditions for injection were as follows: hydrogen was the carrier gas at $45 \mathrm{~cm} / \mathrm{s}$ (at $215^{\circ} \mathrm{C}$ ); the column flow was $1.3 \mathrm{~mL} / \mathrm{min}$; the temperature was $250^{\circ} \mathrm{C}$ in split mode (ratio $1: 25$ ); and the oven temperature was isothermal at $215^{\circ} \mathrm{C}$. The methanol concentration $(\mathrm{MeOH})$ in pectin powders was determined according to Renard and Ginies (2009) by Headspace-GC-MS after saponification. Samples $(10 \mathrm{mg})$ were dissolved or suspended in $3.8 \mathrm{~mL}$ of distilled water and then saponified by the addition of $0.8 \mathrm{~mL}$ of $1 \mathrm{~mol} / \mathrm{L} \mathrm{KOH}$ containing $\mathrm{CD}_{3} \mathrm{OH}(1.4 \mu \mathrm{mol} / \mathrm{mL})$ as an internal standard, and incubated for $2 \mathrm{~h}$ at room temperature. For GC, a Shimadzu QP2010 GC-MS was used with a Cp-wax-52cb $30 \mathrm{~m} \times 0.32 \mathrm{~mm} \times 0.5 \mu \mathrm{m}$ capillary column (Varian, Inc., Palo Alto, USA) equipped with an AOC5000 auto sampler. A sealed vial was placed at $50{ }^{\circ} \mathrm{C}$ for $15 \mathrm{~min}$ and then $0.5 \mathrm{~mL}$ of head-space was injected into the split injector (1:10 ratio). The GC conditions were as follows: helium as gas carrier at $45 \mathrm{~cm} / \mathrm{s}$ and oven temperature at $40^{\circ} \mathrm{C}$ (isothermal). The mass detector conditions were: electronic impact ionization mode $(70 \mathrm{eV})$, temperature of source $200{ }^{\circ} \mathrm{C}$ with data collected using SIM for selected ions $(\mathrm{m} / \mathrm{z} 31$; $32 ; 35$ ) at 5 scans/s. The degree of methylation (DM) was calculated as the molar ratio of methanol to uronic acid.

The uronic acid content (against a galacturonic acid standard) was determined colorimetrically at $520 \mathrm{~nm}$ in both peel and pectin powders by the meta-hydroxyl-diphenyl assay according to Blumenkrantz and Asboe-Hansen (1973) after saponification (see the methanol assay).

\subsection{FT-IR analysis of extracted pectins}

Fourier Transform Infrared (FT-IR) spectra of pectin samples were obtained at room temperature with a Tensor 27 FTIR spectrometer (Bruker Optics, Wissembourg, France) equipped with a single-reflectance horizontal ATR cell (Golden Gate equipped with a diamond crystal, Bruker Optics). The freeze-dried homogenized samples were placed at the surface of the diamond crystal and were pressed with a system press tip flap. The samples were scanned at wavenumbers ranging from 4000 to $650 \mathrm{~cm}^{-1}$ and corrected against the background spectrum of air. The spectrum of each sample was obtained by taking the average of 16 scans.

\subsection{Hydrodynamic volume of extracted pectins}

The hydrodynamic volume distribution of pectin samples were determined using a high pressure size exclusion chromatography (HPSEC) system comprising a Jasco LC-NET II/ADC interface, a Jasco PU-2080 plus intelligent HPLC pump, a Jasco RI-2031 plus 
intelligent RI detector, and a degasser, and was controlled by ChromNav software (Jasco, Tokyo, Japan). Separations were achieved using two columns in series: a $8.0 \mathrm{~mm} \times 300 \mathrm{~mm}$ i.d. OH-pack SB-802 HQ column (Showa Denko Europe, Munich, Germany) and a $300 \times 7.8 \mathrm{~mm}$ i.d. TSK-Gel PWXL column (Tosohaas, Stuttgart, Germany) at $35^{\circ} \mathrm{C}$ and a $40 \times 6.0 \mathrm{~mm}$ i.d. guard column TSK-Gel PWXL (Tosohaas, Stuttgart, Germany). Solutions $(20 \mu \mathrm{L})$ of the extracts $(0.5 \%)$ were injected and eluted with $0.4 \mathrm{~mol} / \mathrm{L}$ sodium acetate buffer $\mathrm{pH} 3.5$ at $0.8 \mathrm{~mL} / \mathrm{min}$. Dextrans T500 and T40 (Pharmacia BioProcess Technology, Uppsala, Sweden) and glucose (Sigma-Aldrich, Deisenhofen, Germany) were used to calibrate the column system. All data are presented as a function of elution time of the samples (ET).

\subsection{Viscometry of extracted pectins}

Reduced viscosities were determined using $0.125 ; 0.25 ; 0.5$; 0.75 and $1 \mathrm{~g} / \mathrm{L}$ pectin solutions prepared in $0.1 \mathrm{~mol} / \mathrm{L}$ sodium phosphate buffer ( $\mathrm{pH} \mathrm{7)}$. After dissolution under stirring at ambient temperature for $12 \mathrm{~h}$, the solutions were filtered $(0.45 \mu \mathrm{m})$. The viscosities of pectin solutions at different concentrations were determined at $20^{\circ} \mathrm{C}$ by means of a rheometer (Physica MCR 301: Anton Paar, Germany) using a double gap DG26.7.

The specific viscosity $\left(\eta_{\mathrm{sp}}\right)$ of a macromolecular solution is defined by Eq. (1).

$\eta_{\mathrm{sp}}=\frac{\left(\eta_{\mathrm{s}}-\eta_{0}\right)}{\eta_{0}}$

The viscosity of the solution is $\eta_{s}$, whereas the viscosity of the solvent is $\eta_{0}$. The reduced viscosity $\left(\eta_{\text {red }}\right)$ of a macromolecule in solution is defined by Eq. (2).

$\eta_{\text {red }}=\frac{\eta_{\mathrm{sp}}}{C}$

Here, $\mathrm{C}$ is the concentration of the macromolecule.

\subsection{Rheological properties of pectin gels}

\subsubsection{Preparation of pectin gels}

For gel preparation at $\mathrm{pH} 7,0.116 \mathrm{~g}$ of pectin powders were dispersed into $15.21 \mathrm{~mL}$ of distilled water and mixed for $120 \mathrm{~min}$ at $20^{\circ} \mathrm{C}$, in order to get a complete hydration. The $\mathrm{pH}$ was adjusted to 7.1-7.2 with sodium citrate solution. The pectin solutions were heated to $85{ }^{\circ} \mathrm{C}$, upon which $0.0087 \mathrm{~g}$ of calcium chloride dihydrate $\left(\mathrm{CaCl}_{2} \cdot 2 \mathrm{H}_{2} \mathrm{O}\right)$, dissolved in $1 \mathrm{~mL}$ of water, was added under magnetic stirring for $5 \mathrm{~min}$. The final pectin concentration was $0.7 \%$ $(\mathrm{w} / \mathrm{v})$, while the final calcium concentration was $0.04 \%$.

For gel preparation at $\mathrm{pH} 3$, dry pectin powder $(0.106 \mathrm{~g})$ was dissolved in $12.2 \mathrm{~mL}$ of citrate buffer $\mathrm{pH} 3$ (citric acid $0.45 \%$ and sodium citrate $0.1 \%$ ) and stirred for $120 \mathrm{~min}$ at $20^{\circ} \mathrm{C}$. The mixtures were then heated, saccharose was added in 3 portions to a final concentration of $30 \%$ and the solution was heated once more until boiling. Afterwards, $0.026 \mathrm{~g}$ of calcium chloride dihydrate $\left(\mathrm{CaCl}_{2} \cdot 2 \mathrm{H}_{2} \mathrm{O}\right)$, dissolved in $1 \mathrm{~mL}$ of water, was added with a final concentration of $0.1 \%$ and mixed under intense stirring. The solution was boiled again. The final pectin concentration was $0.7 \%$.

\subsubsection{Rheological measurements}

The applied rheometer was a Physica MCR 301 (Anton Paar, Germany). Oscillation measurements (temperature sweep) of storage modulus $G^{\prime}$ and loss modulus $G^{\prime \prime}$, in the linear viscoelastic domain, were made using a double gap DG26.7. Pectin gels prepared at $\mathrm{pH} 7$ and $\mathrm{pH} 3$ were transferred on to the pre-heated rheometer at $80^{\circ} \mathrm{C}$ and $90^{\circ} \mathrm{C}$, respectively, and cooled to $10^{\circ} \mathrm{C}$ with a cooling rate of $2{ }^{\circ} \mathrm{C} / \mathrm{min}$. The sample was coated with silicone oil and the cylinder was closed with a special lid in order to avoid evaporation. Dynamic rheological parameter ( $\mathrm{G}^{\prime}$ and $\mathrm{G}^{\prime \prime}$ ) were recorded during cooling at a frequency of $1 \mathrm{~Hz}$ and deformation amplitude of $\gamma 0.1 \%$.

\subsection{Statistical analysis}

Experiments were conducted in triplicate and the differences between treatment means were determined by Duncan's procedure at $\mathrm{P}<0.05$ using the SPSS statistics 19 . The expressed values are means \pm standard deviation of triplicate measurements.

Applied on FT-IR spectral data, principal component analysis (PCA) usually allows to discriminate contrasted samples and group similar samples according to their physico-chemical properties. The Spectral preprocessing and multivariate data analysis were performed with Matlab 7.5 (Mathworks Inc. Natick, MA) software using SAISIR package (Cordella \& Bertrand, 2014). The absorption band around $2400 \mathrm{~cm}^{-1}$, due to carbon dioxide, was discarded. Spectra were systematically pre-treated by standard normal variate correction (SNV).

\section{Results and discussion}

\subsection{Composition of pomegranate peel}

The results for physicochemical characteristics of pomegranate peel from different ecotypes are displayed in Table 1. Moisture content in peel ranged from $67.26 \%$ in Ac ecotype to $73.23 \%$ in Ga ecotype. It can be noticed that the peel of pomegranate of all ecotypes is devoid of fat. The ash content ranged from 3.71 to $4.97 \% \mathrm{dw}$. The protein content in (Ga) ecotype is significantly higher than that of other ecotypes $(7.13 \% \mathrm{dw})$. This value is also higher than that found in other Turkish cultivars, 'Lefon', 'Seedless', 'Kadi', 'Siyah' and 'Koycegiz', whose contents are 3.19; 3.11; 3.06; 2.67 and $2.58 \% \mathrm{dw}$, respectively (Hepaksoy, Aksoy, Can, \& Ui, 2000).

Total sugars, which account for $30.65-34.83 \%$ of the pomegranate peel, consist mainly of soluble fraction $(27.33-32.33 \% \mathrm{dw})$ which is significantly higher than that insoluble $(2.49-3.31 \% \mathrm{dw})$. Pomegranate peel contained higher amount of sugars than that of the skin of yellow and purple cultivars of passion fruit: 25 and 28\%; respectively (Espiard, 2002). Neutral sugar contents accounted for $29.91-31.00 \%$. These amounts are lower than those found in mango and lime peels: 37 and $41 \%$, repectively (Koubala et al., 2008). Glucose (Glc) (probably of cellulosic origin) was the main neutral sugar in pomegranate peel followed by mannose (Man) and xylose (Xyl). Arabinose (Ara), galactose (Gal), rhamnose (Rha) and fucose (Fuc) were also detected but in lower amounts. Low amounts of uronic acid were detected $(<8 \%)$, lower than in apple pomace, sugar beet pulp or citrus peels where uronic acids account for $20-30 \%$ of the dry weight (DW) (Rinaudo, 1996).

The peel of pomegranate contained considerable contents of fibres ranging from 28.10 to $33.93 \%$, respectively, in cultivars Ga and To. These quantities are much higher than those found in the peels of lemons, oranges and grapefruit; $14,13.9$ and $13.9 \%$; respectively (Gorinstein et al., 2001), linked for a large part to a less hydrated nature of the pomegranate peel. Pomegranate peel could be considered so as a rich source of dietary fibre especially of insoluble fibres which ranged between 27.11 and $32.51 \% \mathrm{dw}$.

\subsection{FT-IR spectra of pomegranate peel pectins}

The FT-IR spectra of pomegranate peel pectins, scanned at wavenumbers ranging from 4000 to $650 \mathrm{~cm}^{-1}$ and corrected against the background spectrum of air, are presented in Fig. 1A. These spectra were systematically pre-treated by standard normal 
Table 1

Composition of the four selected pomegranate peels.

\begin{tabular}{|c|c|c|c|c|}
\hline Parameters & Ac & $\mathrm{Ga}$ & $\mathrm{Ne}$ & To \\
\hline Moisture (\%) & $67.26 \pm 0.23^{a}$ & $73.23 \pm 0.15^{\mathrm{b}}$ & $72.58 \pm 0.67^{\mathrm{b}}$ & $72.68 \pm 0.79^{b}$ \\
\hline Proteins (\% DW) & $3.96 \pm 0.49^{\mathrm{a}}$ & $7.13 \pm 0.53^{c}$ & $5.42 \pm 0.01^{\mathrm{b}}$ & $5.84 \pm 0.38^{\mathrm{b}}$ \\
\hline Fat $(\% \mathrm{DW})$ & - & - & - & - \\
\hline Total sugar (\% DW) & $30.65 \pm 0.70^{\mathrm{a}}$ & $33.58 \pm 0.21^{\mathrm{ab}}$ & $33.00 \pm 2.99^{\mathrm{ab}}$ & $34.83 \pm 0.79^{b}$ \\
\hline Solubles & $27.33 \pm 0.70^{\mathrm{a}}$ & $30.60 \pm 0.79^{b}$ & $30.14 \pm 2.99^{\mathrm{ab}}$ & $32.33 \pm 0.21^{\mathrm{b}}$ \\
\hline Insolubles & $3.31 \pm 0.07^{\mathrm{ab}}$ & $2.98 \pm 0.37^{\mathrm{ab}}$ & $2.86 \pm 0.04^{\mathrm{ab}}$ & $2.49 \pm 0.44^{\mathrm{a}}$ \\
\hline Total fibre (\% DW) & $28.27 \pm 0.90^{\mathrm{a}}$ & $28.10 \pm 1.20^{\mathrm{a}}$ & $33.81 \pm 0.42^{\mathrm{b}}$ & $33.93 \pm 0.66^{\mathrm{b}}$ \\
\hline Insolubles & $27.11 \pm 0.65^{a}$ & $27.04 \pm 0.77^{a}$ & $32.51 \pm 0.36^{\mathrm{b}}$ & $32.13 \pm 0.46^{\mathrm{b}}$ \\
\hline Solubles & $1.16 \pm 0.11^{\mathrm{ab}}$ & $1.06 \pm 0.04^{\mathrm{a}}$ & $1.35 \pm 0.21^{\mathrm{b}}$ & $1.80 \pm 0.09^{c}$ \\
\hline Ash (\% DW) & $4.97 \pm 0.22^{\mathrm{b}}$ & $4.44 \pm 0.31^{\mathrm{ab}}$ & $3.71 \pm 0.37^{\mathrm{a}}$ & $4.52 \pm 0.75^{\mathrm{ab}}$ \\
\hline Anhydrouronic acid content (pectin) (\% DW) & $6.63 \pm 0.40^{\mathrm{b}}$ & $7.86 \pm 0.80^{\mathrm{a}}$ & $7.58 \pm 0.33^{\mathrm{a}}$ & $6.45 \pm 0.23^{\mathrm{b}}$ \\
\hline TNS $(\% \mathrm{DW})$ & $31.00 \pm 0.24^{\mathrm{a}}$ & $30.40 \pm 1.97^{\mathrm{a}}$ & $30.34 \pm 0.42^{\mathrm{a}}$ & $29.91 \pm 0.85^{\mathrm{a}}$ \\
\hline Rha & $0.24 \pm 0.00^{c}$ & $0.30 \pm 0.01^{\mathrm{a}}$ & $0.28 \pm 0.00^{\mathrm{b}}$ & $0.28 \pm 0.02^{\mathrm{a}}$ \\
\hline Fuc & $0.05 \pm 0.00^{\mathrm{a}}$ & $0.04 \pm 0.06^{\mathrm{a}}$ & $0.07 \pm 0.00^{\mathrm{a}}$ & $0.07 \pm 0.00^{\mathrm{a}}$ \\
\hline Ara & $1.4 \pm 0.07^{\mathrm{d}}$ & $1.92 \pm 0.05^{\mathrm{a}}$ & $1.51 \pm 0.10^{\mathrm{c}}$ & $1.67 \pm 0.05^{\mathrm{b}}$ \\
\hline Xyl & $1.73 \pm 0.14^{\mathrm{b}}$ & $2.65 \pm 0.19^{a}$ & $2.48 \pm 0.48^{a}$ & $2.95 \pm 0.13^{\mathrm{a}}$ \\
\hline Man & $7.91 \pm 0.10^{\mathrm{a}}$ & $5.97 \pm 0.40^{\mathrm{b}}$ & $4.72 \pm 0.12^{\mathrm{c}}$ & $5.50 \pm 0.13^{\mathrm{b}}$ \\
\hline Gal & $0.99 \pm 0.01^{\mathrm{a}}$ & $1.07 \pm 0.13^{\mathrm{a}}$ & $0.78 \pm 0.01^{\mathrm{b}}$ & $0.98 \pm 0.04^{\mathrm{a}}$ \\
\hline Glc & $18.67 \pm 0.20^{b}$ & $18.44 \pm 1.50^{\mathrm{b}}$ & $20.49 \pm 0.06^{\mathrm{a}}$ & $18.44 \pm 0.74^{\mathrm{b}}$ \\
\hline
\end{tabular}

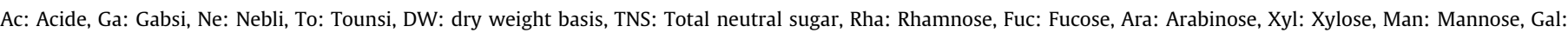

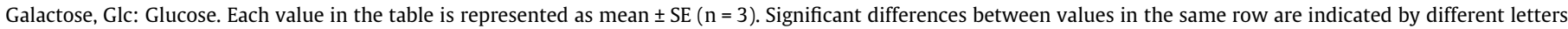
$(\mathrm{P}<0.05)$.

variate correction (SNV). Typical bands appeared in the spectra, as it is expected for pectin molecules, which prove that the extracted substances are pectins.

The region between $3600 \mathrm{~cm}^{-1}$ and $2500 \mathrm{~cm}^{-1}$ presents two major peaks. The first, centered at about $3309 \mathrm{~cm}^{-1}$, corresponds to the absorption caused by $\mathrm{OH}$ stretching absorption due to inter- and intra- molecular hydrogen bonds. In the case of pectin samples, absorption in the $\mathrm{O}-\mathrm{H}$ region was due to inter- and intra- molecular hydrogen bonding of the galacturonic acid backbone. The second peak, centered at about $2935 \mathrm{~cm}^{-1}$, refer to $\mathrm{C}-\mathrm{H}$ absorption, these include $\mathrm{CH}, \mathrm{CH}_{2}$ and $\mathrm{CH}_{3}$ stretching and bending vibrations.

Below $1500 \mathrm{~cm}^{-1}$, the moderately intense absorption patterns are considered as the "fingerprint" region for pectins and the absorptions cannot unambiguously be assigned to any particular vibration because they correspond to complex interacting vibrating systems. Bands occurring in this region at 994, 1076, 1219 and $1439 \mathrm{~cm}^{-1}$ are $\mathrm{C}-\mathrm{O}$ stretching, $\mathrm{C}-\mathrm{C}$ stretching; $\mathrm{C}=\mathrm{O}$ stretching; $\mathrm{C}-\mathrm{O}$ stretching and asymmetric stretching modes of $\mathrm{CH}_{3}$, respectively (Szymanska-Chargot \& Zdunek, 2013). Adina, Florinela, Abdelmoumen, and Carmen (2010) reported that glucose, fructose and sucrose show intense and characteristic bands in the region between 1200 and $900 \mathrm{~cm}^{-1}$ with peaks registered at 1033, 1063 and $995 \mathrm{~cm}^{-1}$, respectively.

The third region between 1800 and $1500 \mathrm{~cm}^{-1}$ is of special interest with regards to the evaluation of the degree of methylation, since it allows the observation of infrared absorption by the carboxylic acid and the carboxylic ester groups of the pectin molecules. The examination of this spectral region reveals the existence of two bands centered at $1731 \mathrm{~cm}^{-1}(\mathrm{C}=\mathrm{O}$, ester carbonyl groups stretching) and $1619 \mathrm{~cm}^{-1}$ ( $\mathrm{COO}^{-}$carboxylate ion stretching band) (Szymanska-Chargot \& Zdunek, 2013).

To further identify relevant spectral patterns, the spectra were submitted to principal component analysis (PCA). The plot of the scores of Principal Components (PCs) allows discrimination of different groups of samples. The scatter plot of the scores of the two first principal components PC1 and PC2, which together explain $74.5 \%$ of the total variability, were used to obtain separation of each group in the $4000-650 \mathrm{~cm}^{-1}$ region (Fig. 1B). The scores are scattered along PC1. Along PC1 axis, pectins extracted from different varieties seemed to be grouped according to their DM. The scores of Ac and To (having lower DM) lay on the positive side of
PC1 scores, while Ne and Ga (with higher DM) were on the negative side of PC1. Indeed, the load of the PC1 plot vs wavenumber showed that the negative high values of PC1 were obtained for wavenumbers at $1619 \mathrm{~cm}^{-1}$ and $1219 \mathrm{~cm}^{-1}$ assigned, respectively, to the absorption of the non-esterified carboxyl groups and $\mathrm{C}-\mathrm{O}$ stretching of the pectin molecules (Fig. 1C). Positive loadings for PC1 cover wavenumber at $994 \mathrm{~cm}^{-1}$ assigned to $\mathrm{C}-\mathrm{O}$ stretching/ C-C stretching (Szymanska-Chargot \& Zdunek, 2013).

\subsection{General composition of pomegranate peel pectins}

In our literature review, we have not found previous works reporting on the pectin content of pomegranate peel. Therefore, we compared our data with those available for commonly known sources of pectins.

The extracted pectin yield, at $86^{\circ} \mathrm{C}, 80 \mathrm{~min}$ and at $20 \mathrm{mmol} / \mathrm{L}$ nitric acid ( $\mathrm{pH} 1.7$ ), ranged from 6.81 to $10.12 \%$ of the dry weight of the peel (Table 2). The highest yield was obtained for the variety $\mathrm{Ga}(\mathrm{P}<0.05)$. The two commercial sources of pectins (apple pomace and citrus peel) give yields of circa $10-15 \%$ and $20-30 \%$ on a dry matter basis, respectively (Kanmani, Dhivya, Aravind, \& Kumaresan, 2014). Compared to the literature data, the pectin yields were close to those of Kulkarni and Vijayanand (2010) extracted from passion fruit peel (9\%) under comparable conditions $\left(90^{\circ} \mathrm{C}, 60 \mathrm{~min}, \mathrm{pH} 2\right)$. On the other hand, the values were lower than those reported by Sanchez-Aldana, Aguilar, NevarezMoorillon, and Contreras Esquivel (2013) from mexican lime pomace $\left(90^{\circ} \mathrm{C}, 60 \mathrm{~min}, 1 \%\right.$ citric acid solution) (15\%). Previous studies proved that the different extraction methods and the different origins of pectins highly affected the pectin yields (Wang et al., 2015; Müller-Maatsch et al., 2016).

The chemical composition of extracted pectins is shown in Table 2. The uronic acid contents (AUA) of Ac, Ga, Ne and To were $47.71 ; 47.05 ; 61.32$ and $68.51 \%$, respectively (on a dry-weight basis). Only the extract from To could legally be labeled as pectin (>65\% GalA), 1981), however these values were close to those observed from apple pomace pectin (53-75\%) (Fertonani et al., 2006).

Another characteristic of pectin is the rhamnose: galacturonic acid ratio which can be used a as surrogate to assess the rhamnogalacturonan to homogalacturonan ratio. The values of the molar ratios of uronic acid to Rha, as shown in Table 2, were high. This 

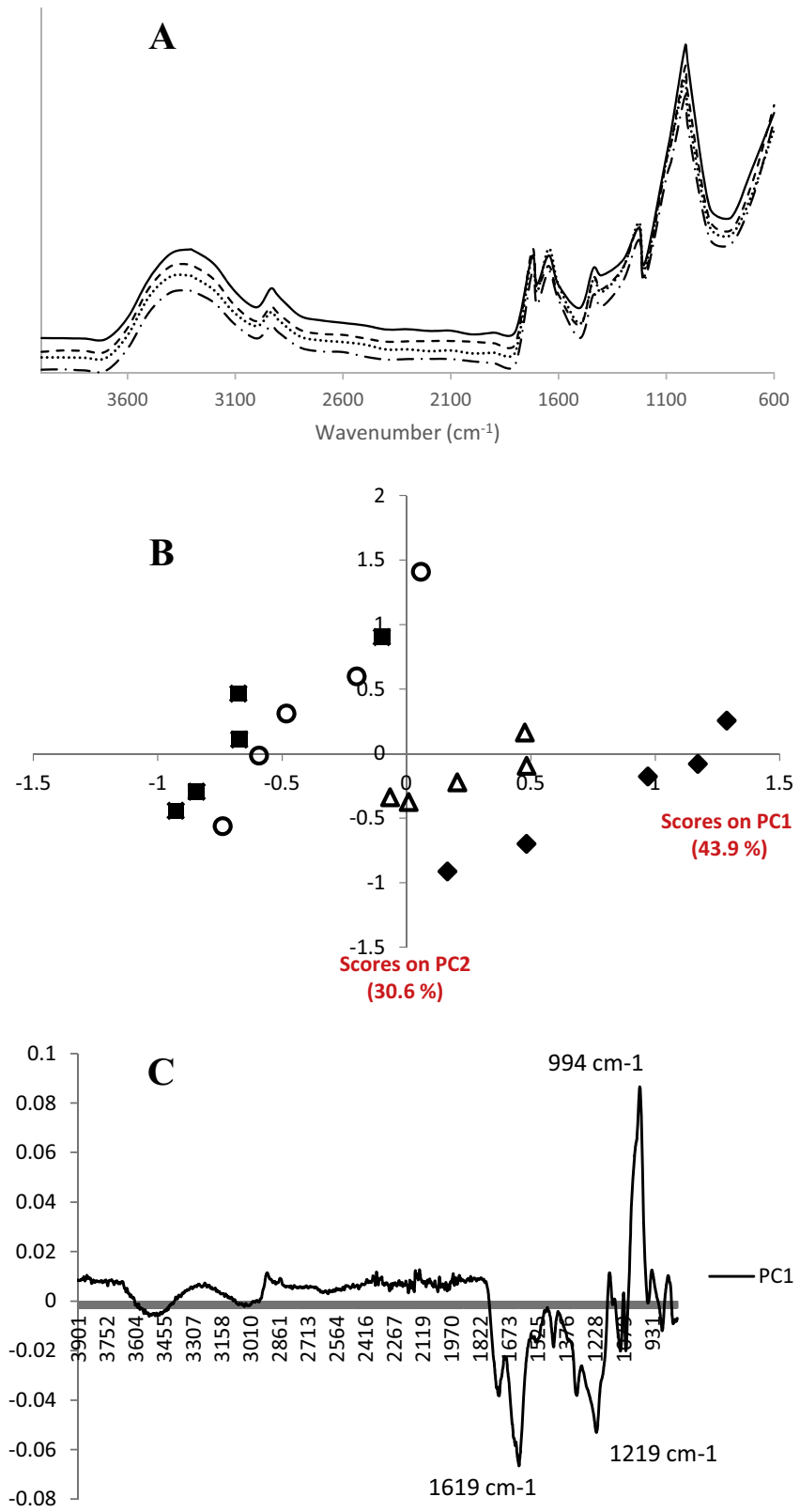

Fig. 1. Analysis of pomegranate peel pectin by FT-IR. (A) FT-IR spectra of pectins from pomegranate peel: Acide (-), Gabsi (---.), Nebli (----), Tounsi (--); (B) PCA scores scatter plots of pectin from pomegranate peel FT-IR spectra in the 4000$650 \mathrm{~cm}^{-1}$ region: Acide $(\bullet)$, Gabsi $(O)$, Nebli $(\square)$, Tounsi $(\triangle)$; (C) PCA loadings plots (first principal component) of pectin from pomegranate peel FT-IR spectra in the $4000-650 \mathrm{~cm}^{-1}$ region.

ratio varies widely across pectin sources, from 3.4 for soybean pectin (Benoit et al., 2012), mostly containing rhamnogalacturonans, to 74 in commercial citrus pectins (Taboada et al., 2010), characterized by the predominance of long homogalacturonan regions. The ratios obtained here for Ac and Ga ecotypes are similar to those reported for murta pectin (66) (Taboada et al., 2010), indicating the predominance of homogalacturonans. On the other hand, this ratio was higher for the pectin extracted from the To variety, suggesting that this pectin contained probably an even lower proportion of rhamnogalacturonic regions.

Furthermore, if the molar ratio of Rha to (Ara and Gal) taken altogether is indicative of the degree of side chain abundance and length, then the Ac variety seemed the most branched product 
compared to other varieties, given that it had a low value of GalA/ Rha along with a low value of Rha/(Ara + Gal) molar ratios.

The proportion of methoxylated carboxyl groups (degree of methoxylation DM) is very important as it can determine the mechanism of formation of pectin gels, their conformation and rheological properties. Ac has significantly lower DM (34\%) compared to that of $\mathrm{Ga}$ and Ne varieties with DM of $46 \%$ and $41 \%$ (Table 2). The DM was inferior to $50 \%$ in all samples, indicating that the four extracted pectins were low methylated (LM). Generally such pectins, particularly low methoxyl amidated (LMA) pectin, are preferred for low-calorie product formulas. LM pectins may form gels in the presence of calcium in slightly acidic to neutral $\mathrm{pH}$ with or without sugar, contrary to HM pectins which require high sugar content $(\sim 65 \%)$ and a $\mathrm{pH}<3.5$ (Thakur, Singh, \& Handa, 1997) to form gels by a combination of hydrophobic interactions (at higher temperature) and hydrogen bonds between undissociated carboxyl groups (at lower temperature).

The total neutral sugar (TNS) content in pomegranate peel pectins ranged from 12.18 to $29.52 \%$. This amount was comparable to that of apple pomace extracted at $90{ }^{\circ} \mathrm{C}$ and $\mathrm{pH} 1.5$ for $1 \mathrm{~h}(18.3 \%)$ (Garna et al., 2007). The main neutral sugars found in pomegranate peel pectin were Glc (5.17-23.11\%), Gal (2.86-3.38\%) and Ara (1.82-2.28\%) (Table 2). Neutral sugars in this study were comparable to composition previously reported for apple pomace pectin (10.9, 3.2 and $1.1 \%$ for Glc, Gal and Ara, repectively) (Garna et al., 2007).

The origin of the glucose in pomegranate peel pectin is not clear: residual starch or sugar might be present in the pomegranate peels. Apart from rhamnose, arabinose and galactose, which are included in the pectin's structure, other neutral sugars, such as fucose, xylose and mannose were present, but in low amounts and were therefore assumed to be "contaminants" from hemicellulosic and sugar materials. Similar findings were reported by Garna et al. (2007): low amounts of xylose and mannose with high glucose content were detected. In addition, the galactose content of all extracts was higher than that of arabinose suggesting the predominance of arabinogalactan side chains.

Pectin extracted from Ac variety was richer in neutral sugars than other cultivars. Compared with the raw peels, pomegranate peel pectins were enriched in rhamnose, galactose and arabinose and impoverished in glucose, xylose and mannose (Tables 1 and 2). This difference in neutral sugar content between the raw peels and the extracted pectins can be attributed to the degradation of some sugars during the extraction at acidic $\mathrm{pH}$. Garna et al. (2007) reported that the neutral sugar side chains of pectins and glycosidic linkages of some polymers (for example the hemicellulose) can undergo a partial hydrolysis during the extraction in free sugars or in small molecular weight compounds that will not be precipitated with the ethanol.

\subsection{The hydrodynamic volume distribution of pomegranate peel pectins}

The hydrodynamic volume distribution of different samples was determined by HPSEC (Voragen et al., 1995). The elution times (ET) at peak summit and the partition coefficients (Kav) are listed in Table 2, and Fig. 2 shows the HPSEC profiles.

The pectin extracted from Ac ecotype was distinguished by the higher partition coefficient (Kav of -0.005 ) with the longest elution time (ET = $15.07 \mathrm{~min}$ ) which reflects the lowest hydrodynamic volume. Whereas this sample had hydrodynamic volume higher than those of dextranes T500 and glucose with elution times (ET) of 15.11 and $23.00 \mathrm{~min}$, respectively. In all ecotypes, the pectin samples showed a relatively high polydispersity, characterized by the presence of a tail of smaller molecules. In addition to the primary effect of degree of polymerization, Fishman, Pfeffer

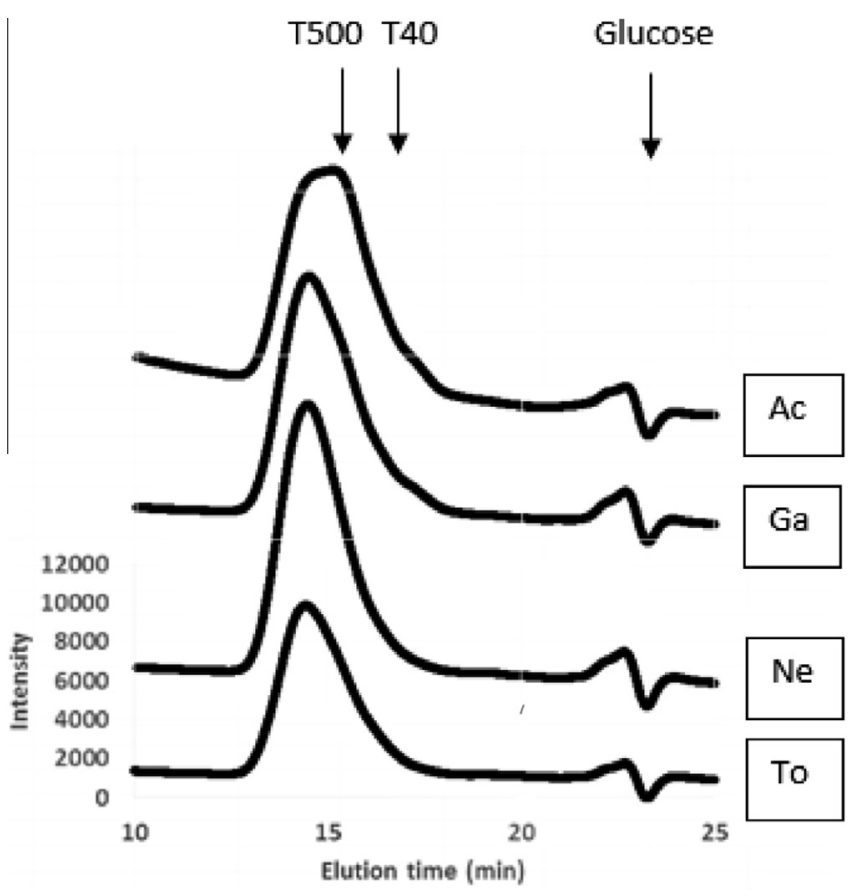

Fig. 2. High-pressure size-exclusion chromatography elution profiles of pectins extracted from pomegranate peel. Ac: Acide ecotype; Ga: Gabsi ecotype; Ne: Nebli ecotype; To: Tounsi ecotype.

Barford, and Doner (1984) reported that degree of methylation could affect pectin hydrodynamic volume by affecting the strength of intermolecular ionic repulsions and the character of the attractive forces between chains; however all pomegranate pectins had similar degrees of methylation. The differences observed in the HPSEC patterns was thus likely to reflect different chain lengths of the pectins from the four raw materials.

\subsection{Pectin viscosity}

Fig. 3 contains typical Huggins plots of reduced viscosity $\left(\eta_{\text {red }}\right)$ against pectin concentration. All samples of pectin exhibited a pseudo-hyperbolic pattern with a continual increase in molecular volume with dilution. This data is consistent with earlier work (Fishman, Gillespie, Sondey, \& Barford, 1989) which showed that the increase in size with decreasing pectin concentration is a sequential process: as the concentration of pectin increased, smaller sized species appeared. Increasing size with dilution could be attributed to the formation of large spherical networks or to the polyelectrolyte expansion due to an increase in charge-charge repulsions along the chain.

\subsection{Rheological study}

Gel formation was monitored in two steps. First, the temperature was decreased linearly from $90^{\circ} \mathrm{C}$ to $10^{\circ} \mathrm{C}$ at $2{ }^{\circ} \mathrm{C} / \mathrm{min}$, then, this temperature was maintained for $30 \mathrm{~min}$. Variations of elastic modulus $\left(\mathrm{G}^{\prime}\right)$ and viscous modulus $\left(\mathrm{G}^{\prime \prime}\right)$ as a function of temperature are shown in Fig. $4 \mathrm{~A}$ for $\mathrm{LM}$ pectins of varieties Ac, Ga, Ne and To at $\mathrm{pH} 3$, in the presence of $0.7 \%$ pectin $(\mathrm{w} / \mathrm{w})$ and $0.1 \% \mathrm{CaCl}_{2}$. Fig. $4 \mathrm{~A}$ revealed the formation of a cross-linked network, which was characterized by the temperature independence of $G^{\prime}$ and $G^{\prime \prime}$ on cooling. As a matter of fact, during cooling from $90^{\circ} \mathrm{C}$ to $10^{\circ} \mathrm{C}$, no crossover between the storage modulus $\left(\mathrm{G}^{\prime}\right)$ and the loss modulus $\left(G^{\prime \prime}\right)$ occured. It is worth noting that all gels show a rapid gel formation with $G^{\prime}>G^{\prime \prime}$, which reveals a typically gel-like 

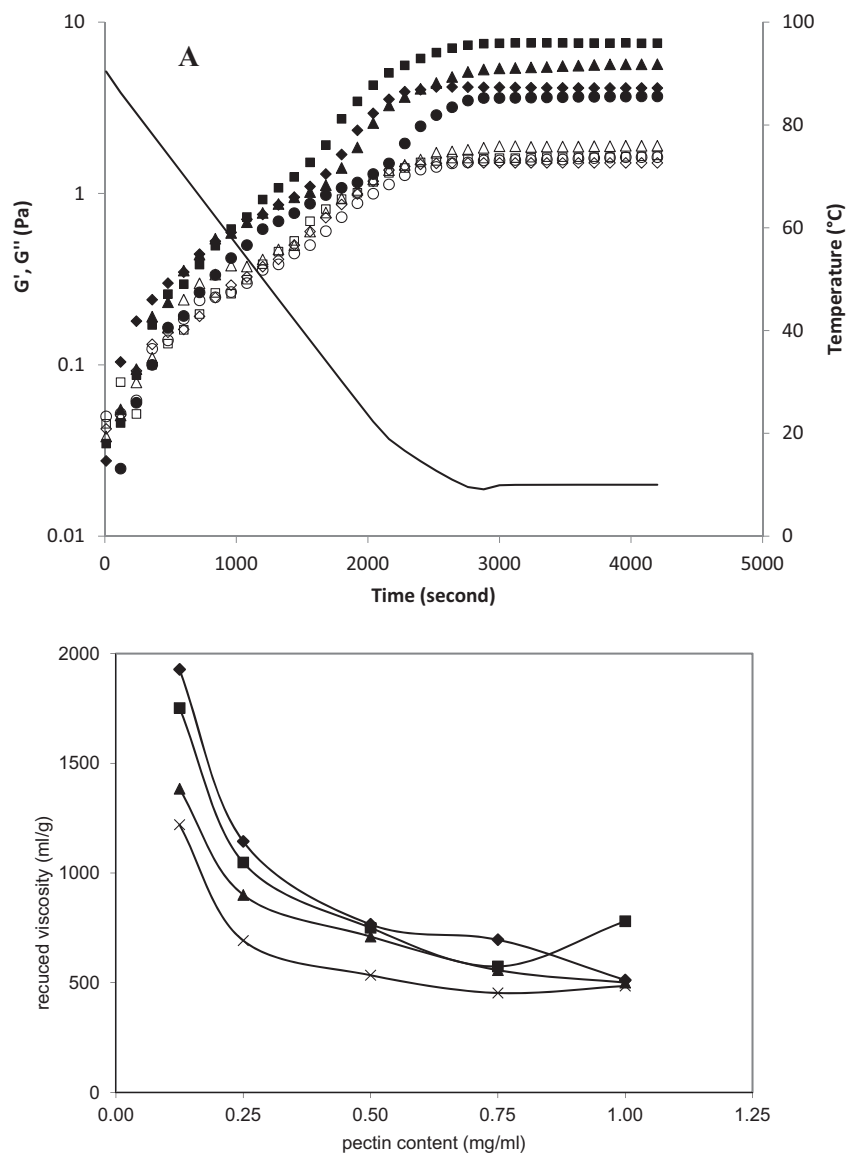

Fig. 3. Huggins plot of pectins in $0.1 \mathrm{~mol} / \mathrm{L}$ sodium phosphate buffer (pH7). Acide $(\times)$, Gabsi $(\boldsymbol{\Lambda})$, Nebli $(\boldsymbol{\square})$, Tounsi $(\bullet)$.

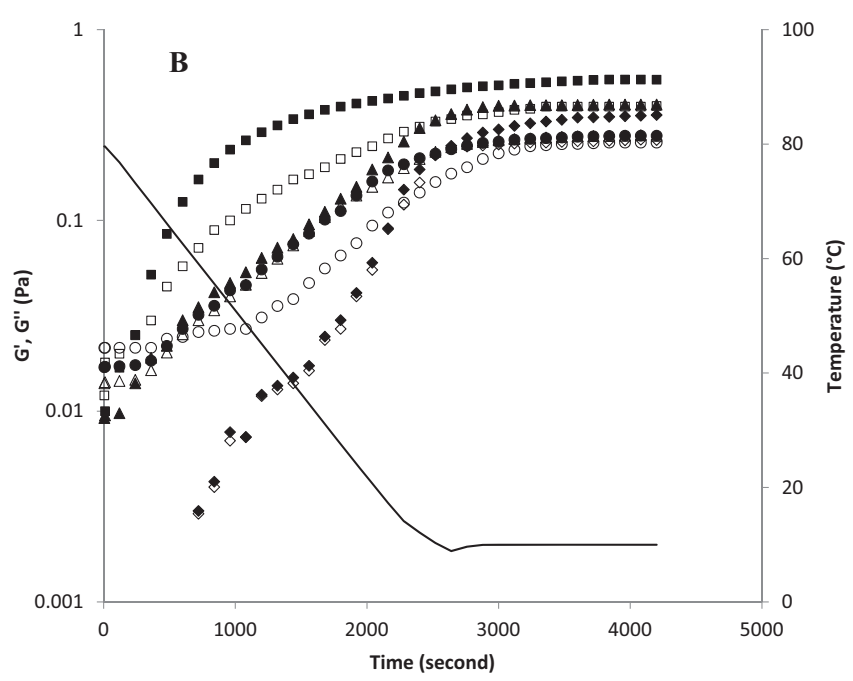

Fig. 4. Semi-logarithmic plots of $\mathrm{G}^{\prime}$ and $\mathrm{G}^{\prime \prime}$ vs time obtained at constant frequency $(1 \mathrm{~Hz})$ during controlled cooling $\left(2^{\circ} \mathrm{C} / \mathrm{min}\right)$ of pectin gels at $\mathrm{pH} 3(\mathrm{~A})$ and $\mathrm{pH} 7(\mathrm{~B})$. $\mathrm{G}^{\prime}$ Ac: $(\diamond), \mathrm{G}^{\prime \prime}$ Ac: $(\diamond), \mathrm{G}^{\prime} \mathrm{Ga}:(\boldsymbol{\Delta}), \mathrm{G}^{\prime \prime} \mathrm{Ga}:(\triangle), \mathrm{G}^{\prime} \mathrm{Ne}:(\bullet), \mathrm{G}^{\prime \prime} \mathrm{Ne}:(\bigcirc), \mathrm{G}^{\prime} \mathrm{To}:(\mathbf{\bullet}), \mathrm{G}^{\prime \prime}$ To: $(\square)$, Temperature: (-).

structure, but the development in $\mathrm{G}^{\prime}$ during the measurement period varied with the variety, reaching the plateau at $10^{\circ} \mathrm{C}$.

For all samples $\mathrm{G}^{\prime}$ increased with decreasing temperature during cooling from $90^{\circ} \mathrm{C}$ to $10^{\circ} \mathrm{C}$, however the To pectin exhibit a significantly higher storage modulus than those of other varieties at the same pectin concentration with greater separation of $G^{\prime}$ and
$\mathrm{G}^{\prime \prime}$. Thus, the gel To was characterized by a denser network with more interconnected chains. This behavior could be attributed to the combination of the low neutral sugar content, the low DM and the high galacturonic acid content of pectin extracted from this ecotype (Tounsi). This could be explained by the fact that sugar side chains in the pectin molecule hinder gel formation by preventing pectins' aggregation (Smidsrod \& Haug, 1971). The presence of methyl groups prevents the formation of junction zones in the interjunction segments of molecules, making them more flexible (Thakur et al., 1997). Moreover, the molecules with an increased number of charged groups and lower degree of methoxylation are straighter than esterified ones, and hence more likely to form a $\mathrm{Ca}^{2+}$ bridge. For the galacturonic acid contribution, the same effect was reported by Rinaudo (1996) who reported that the elastic modulus is directly proportional to the galacturonic acid yield.

The comparison between the different ecotypes showed a variation in the gel formation which could be attributed to difference in pomegranate peel pectin characteristics such as the hydrodynamic volume and the neutral sugar content. Indeed, the strength of the gels obtained for Ac, Ga and To increased with increase in the hydrodynamic volume. Thus, a decrease in the elastic modulus $\left(\mathrm{G}^{\prime}\right)$ can be observed when the degradation of sample was important. These findings were in agreement with the results reported by Kim, Rao, and Smit (1978) for low-ester pectin.

$\mathrm{G}^{\prime}$ was also significantly influenced by the neutral sugar content. As shown in Fig. 4A and Table 2, the storage modulus $\mathrm{G}^{\prime}$ was lower in the presence of higher amount of neutral sugar. The presence of side branches significantly affects gelling property. This can be explained by the fact that neutral side chains in the pectin molecule hinder gel formation by preventing pectins' aggregation (Thakur et al., 1997).

With increasing the $\mathrm{pH}$ to 7 (Fig. 4B), gels exhibited behavior different to those of $\mathrm{pH} 3$. At $\mathrm{pH} 7$, in the presence of $0.7 \%$ pectin and $0.04 \% \mathrm{CaCl}_{2}(3.6 \mathrm{mmol} / \mathrm{L})$, all pectins formed gels with $\mathrm{G}^{\prime}>\mathrm{G}^{\prime \prime}$ at $10^{\circ} \mathrm{C}$, i.e. a typical gel-like structure, however, the shape of the mechanical spectra was that of a weak gel. Gigli, Garnier, and Piazza (2009) also reported that the gel made at similar conditions (DM of pectin 23\%; $\mathrm{pH} 7 ; 1 \%$ pectin and $3 \mathrm{mmol} / \mathrm{L}$ of $\mathrm{CaCl}_{2}$, was a weak gel with $\mathrm{G}^{\prime} \sim 1 \mathrm{~Pa}$.

\section{Conclusions}

In the present study, the four tunisian pomegranate peels studied (Acide, Gabsi, Nebli and Tounsi) appeared relatively low in pectins, as revealed by their low content in uronic acids. The recovered pectins were low methylated (LM) and characterized by the predominance of homogalacturonan regions. The rheological study showed that the extracted pectins present good characteristics to be exploited industrially for their gelling properties in presence of calcium. Indeed, at $\mathrm{pH} 3$ and $\mathrm{pH} 7$ all pectin solutions ( $0.7 \%$ pectin, $30 \%$ sucrose) formed gels with $G^{\prime}>G^{\prime \prime}$ reaching the plateau at $10^{\circ} \mathrm{C}$, i.e. a typical gel-like structure. We are currently investigating the effect of substitution of commercial pectin by that extracted from pomegranate peel on pomegranate jam characteristics. The final product could be enriched with fibre extracted from pomegranate peel.

\section{Acknowledgements}

The authors thank Mrs L. Touloumet for assistance with analytical methods. This work was financed by the Ministry of Higher Education and Scientific Research - Tunisia to Mouna Abid for an internship at UMR408 Sécurité et Qualité des Produits d'Origine Végétale and UMR Ingénierie Procédés Aliments. 


\section{References}

Adina, C., Florinela, F., Abdelmoumen, T., \& Carmen, S. (2010). Application of FTIR spectroscopy for a rapid determination of some hydrolytic enzymes activity on sea buckthorn substrate. Romanian Biotechnological Letters, 15, 5738-5744.

AOAC (1997). Official methods of analysis (16th ed.). Washington, DC: Association of Official Analytical Chemists.

Arslan, N., \& Kar, F. (1998). Filtration of sugar-beet pulp pectin extract and flow properties of pectin solutions. Journal of Food Engineering, 36, 113-122.

Ayed, N. (2011). La pomme de Carthage (Grenade de Tunisie). Le Maghreb Magazine, Tunisie, 2, 98-100.

Benoit, I., Coutinho, P. M., Schols, H. A., Gerlach, J. P., Henrissat, B., \& De Vries, R. P. (2012). Degradation of different pectins by fungi: Correlations and contrasts between the pectinolytic enzyme sets identified in genomes and the growth on pectins of different origin. BMC Genomics, 13, 321-331.

Blumenkrantz, N., \& Asboe-Hansen, G. (1973). New method for quantitative determination of uronic acids. Analytical Biochemistry, 54, 848-849.

Braccini, I., \& Perez, S. (2001). Molecular basis of $\mathrm{Ca}^{2+}$ induced gelation in alginates and pectins: The egg-box model revisited. Biomacromolecules, 2, 1089-1096.

Brett, C. T., \& Waldron, K. W. (1996). Physiology and biochemistry of plant cell wall (2nd ed.). London: Chapman \& Hall.

Cordella, C., \& Bertrand, D. (2014). SAISIR: A new general chemometric toolbox. Trends in Analytical Chemistry, 54, 75-82.

Dubois, M., Gilles, K. A., Hamilton, J. K., Rebers, P. A., \& Smith, F. (1956). Colorimetric method for determination of sugars and related substances. Analytical Chemistry, 28, 350-356.

Englyst, H. N., \& Cummings, J. H. (1984). Simplified method for the measurement of total non-starch polysaccharides by gas-liquid chromatography of constituent sugars as alditol acetates. Analyst, 109, 937-942.

Espiard, E. (2002). Introduction à la transformation industrielle des fruits. TEC\&DOCLavoisier, 174.

Fertonani, H. C. R., Scabio, A., Canteri, M. H. G., Carneiro, E. B. B., Nogueira, A., \& Wosiacki, G. (2006). Influence of acid concentration on extraction and quality of apple pomace pectin. Semina: Ciencias Agrarias, Londrina, 27, 599-612.

Fishman, M. L., Gillespie, D. T., Sondey, S. M., \& Barford, R. A. (1989). Characterization of pectins by size exclusion chromatography in conjunction with viscosity detection. Journal of Agricultural and Food Chemistry, 37, 584-591.

Fishman, M. L., Pfeffer, P. E., Barford, R. A., \& Doner, L. W. (1984). Studies of pectin solution properties by high performance size exclusion chromatography. Journal of Agricultural and Food Chemistry, 32, 372-378.

Garna, H., Mabon, N., Rober, C., Cornet, C., Nott, K., Legros, H., ... Paquot, M. (2007) Effect of extraction conditions on the yield and purity of apple pomace pectin precipitated but not washed by alcohol. Journal of Food Science, 72, C1-C9.

Gigli, J., Garnier, C., \& Piazza, L. (2009). Rheological behaviour of low-methoxyl pectin gels over an extended frequency window. Food Hydrocolloids, 23, 1406-1412.

Gorinstein, S., Martín-Belloso, O., Park, Y. S., Haruenkit, R., Lojek, A., Ĉ́žz, M., ... Trakhtenberg, S. (2001). Comparison of some biochemical characteristics of different citrus fruits. Food Chemistry, 74, 309-315.

Hepaksoy, S., Aksoy, U., Can, H. Z., \& Ui, M. A. (2000). Determination of relationship between fruit cracking and some physiological responses, leaf characteristics and nutritional status of some pomegranate varieties. Cahiers Options Méditerranéennes, 87-92.

Kanmani, P., Dhivya, E., Aravind, J., \& Kumaresan, K. (2014). Extraction and analysis of pectin from citrus peels: Augmenting the yield from citrus limon using statistical experimental design. Iranica Journal of Energy \& Environment, 5 303-312.
Kim, W. J., Rao, V. N. M., \& Smit, C. J. B. (1978). Effect of chemical composition on compressive mechanical properties of low ester pectin gels. Journal of Food Science, 43, 572-575.

Koubala, B. B., Kansci, G., Mbome, L. I., Crépeau, M.-J., Thibault, J.-F., \& Ralet, M.-C. (2008). Effect of extraction conditions on some physicochemical characteristics of pectins from "Améliorée" and "Mango" mango peels. Food Hydrocolloids, 22, 1345-1351.

Kulkarni, S. G., \& Vijayanand, P. (2010). Effect of extraction conditions on the quality characteristics of pectin from passion fruit peel (Passiflora edulis f. flavicarpa L.). LWT Food Science and Technology, 43, 1026-1031.

Logfgren, C., Guillotin, S., Evenbratt, H., Schols, H., \& Hermansson, A.-M. (2005). Effects of calcium, pH and blockiness on kinetic rheological behaviour of HM pectin gels. Biomacromolecules, 6, 646-652.

May, C. (1990). Industrial pectins: Sources, production and applications. Carbohydrate Polymers, 12, 79-99.

Müller-Maatsch, J., Bencivenni, M., Caligiani, A., Tedeschi, T., Bruggeman, G., Bosch, M., ... Sforza, S. (2016). Pectin content and composition from different food waste streams. Food Chemistry, 201, 37-45.

Panichayupakaranant, P., Tewtrakul, S., \& Yuenyongsawad, S. (2010). Antibacterial, anti-inflammatory and anti-allergic activities of standardised pomegranate rind extract. Food Chemistry, 123, 400-403.

Prosky, L., Asp, N. G., Schweizer, T. F., De Vries, J. W., \& Fruda, I. (1988). Determination of insoluble, soluble and total dietary fibre in foods and food products. Journal of the Association of Official Analytical Chemists, 71, 1017-1023.

Qu, W. J., Pan, Z. I., Zhang, R. H., Ma, H. L., Chen, X. G., Zhu, B. N., ... Atungulu, G. G. (2009). Integrated extraction and anaerobic digestion process for recovery of nutraceuticals and biogas from pomegranate marc. Transactions of the ASABE, 52, 1997-2006.

Rao, D. G. (1993). Studies on viscosity-molecular weight relationship of chitosan solutions. Journal of Food Science and Technology, 30, 66-67.

Renard, C. M. G. C., \& Ginies, C. (2009). Comparison of the cell wall composition for flesh and skin from five different plums. Food Chemistry, 114, 1042-1049.

Rinaudo, M. (1996). Physicochemical properties of pectins in solution and gel states. In J. Visser \& A. G. J. Voragen (Eds.), Pectins and pectinases (pp. 21-33). Amsterdam: Elsevier.

Sanchez-Aldana, D., Aguilar, C. N., Nevarez-Moorillon, G. N., \& Contreras Esquivel, J. C. (2013). Comparative extraction of pectic and polyphenols from mexican lime pomace and bagasse. American Journal of Agricultural and Biological Sciences, 8, 309-322.

Smidsrod, O., \& Haug, A. (1971). Estimation of relative stiffness of the molecular chain in polyelectrolytes from measurements of viscosity at different ionic strengths. Biopolymers, 10, 1213-1227.

Szymanska-Chargot, M., \& Zdunek, A. (2013). Use of FT-IR spectra and PCA to the bulk characterization of cell wall residues of fruits and vegetables along a fraction process. Food Biophysics, 8, 29-42.

Taboada, E., Fisher, P., Jara, R., Zú, E., Gidekel, M., Cabrera, J. C., ... Cabrera, G. (2010). Isolation and characterization of pectic substances from murta (Ugni molinae Turcz.) fruits. Food Chemistry, 123, 669-678.

Thakur, B. R., Singh, R. K., \& Handa, A. K. (1997). Chemistry and uses of pectin - A review. Critical Reviews in Food Science and Nutrition, 37, 47-73.

Voragen, A. G. J., Pilnik, W., Thibault, J. F., Axelos, M. A. V., \& Renard, C. M. G. C. (1995). Pectins. In A. M. Sephen (Ed.), Food polysaccharides and their applications (pp. 287-339). New York: Marcel Dekker Inc.

Wang, W., Ma, X., Xu, Y., Cao, Y., Jiang, Z., Ding, T., ... Liu, D. (2015). Ultrasoundassisted heating extraction of pectin from grapefruit peel: Optimization and comparison with the conventional method. Food Chemistry, 178, 106-114. 